\title{
Regional microglial activation in the substantia nigra is linked with fatigue in MS
}

Tarun Singhal, MD, Steven Cicero, BS, Hong Pan, PhD, Kelsey Carter, BS, Shipra Dubey, PhD, Renxin Chu, PhD, Bonnie Glanz, PhD, Shelley Hurwitz, PhD, Shahamat Tauhid, MD, Mi-Ae Park, PhD, Marie Kijewski, DSc, Emily Stern, MD, Rohit Bakshi, MD, MA, David Silbersweig, MD, and Howard L. Weiner, MD

Neurol Neuroimmunol Neuroinflamm 2020;7:e854. doi:10.1212/NXI.0000000000000854

\section{Abstract}

\section{Objective}

The goal of our study is to assess the role of microglial activation in MS-associated fatigue (MSAF) using [F-18] PBR06-PET.

\section{Methods}

Fatigue severity was measured using the Modified Fatigue Impact Scale (MFIS) in 12 subjects with MS ( 7 relapsing-remitting and 5 secondary progressive) and 10 healthy control participants who underwent [F-18]PBR06-PET. The MFIS provides a total fatigue score as well as physical, cognitive, and psychosocial fatigue subscale scores. Standardized Uptake Value (SUV) 60-90 minute frame PET maps were coregistered to 3T MRI. Voxel-by-voxel analysis using Statistical Parametric Mapping and atlas-based regional analyses were performed. SUV ratios (SUVRs) were global brain normalized.

\section{Results}

Peak voxel-based level of significance for correlation between total fatigue score and PET uptake was localized to the right substantia nigra (T-score 4.67, $p=0.001$ ). Similarly, SUVRs derived from atlas-based segmentation of the substantia nigra showed significant correlation with MFIS ( $\mathrm{r}=0.76, p=0.004)$. On multiple regression, the right substantia nigra was an independent predictor of total MFIS $(p=0.02)$ and cognitive MFIS subscale values $(p=0.007)$, after adjustment for age, disability, and depression. Several additional areas of significant correlations with fatigue scores were identified, including the right parahippocampal gyrus, right precuneus, and juxtacortical white matter (all $p<0.05)$. There was no correlation between fatigue scores and brain atrophy and lesion load in patients with MS.

\section{Conclusion}

Substantia nigra microglial activation is linked to fatigue in MS. Microglial activation across key brain regions may represent a unifying mechanism for MSAF, and further evaluation of neuroimmunologic basis of MSAF is warranted.

\author{
Correspondence \\ Dr. Singhal \\ tsinghal@bwh.harvard.edu
}




\section{Glossary}

AAL = automated anatomic labeling; $\mathbf{B P V}=$ brain parenchymal volume; $\mathbf{C F S}=$ chronic fatigue syndrome; CIS = clinically isolated syndrome; DMN = default mode network; EDSS = Expanded Disability Status Scale; ES = effect size; HAB = highaffinity binding; HC = healthy control; HDRS = Hamilton Depression Rating Scale; MAB = medium-affinity binding; RRMS = relapsing-remitting MS; SN = substantia nigra; SPM = Statistical Parametric Mapping; SPMS = secondary progressive MS; TSPO $=$ translocator protein.

Defined as an overwhelming sense of tiredness, lack of energy, or feeling of exhaustion, ${ }^{1,2}$ fatigue is reported as the most disabling symptom in up to $60 \%$ of patients with $\mathrm{MS}^{3}$ and is estimated to have a lifetime prevalence of $80 \% .{ }^{4}$ Moreover, the prevalence of fatigue increases with disease progression ( $46 \%$ in patients with clinically isolated syndrome [CIS] and $80 \%$ in patients with secondary progressive MS $[\mathrm{SPMS}])^{5}$ Importantly, fatigue has been described as the leading cause of absence from work in MS. ${ }^{6}$ Fatigue may also have prognostic implications in patients with MS. For example, in patients with CIS, up to $46 \%$ of patients may present with fatigue, which has recently been shown to predict conversion to clinically definite $\mathrm{MS}^{7}$ Among patients with relapsingremitting MS (RRMS), fatigue scores were higher in patients who converted to a confirmed Expanded Disability Status Scale (EDSS) score $\geq 3$ after at least 3 years of follow-up compared with nonconverters. This association remained significant after adjusting for depression scales and baseline EDSS. ${ }^{8}$ Despite the high prevalence and significance of fatigue in MS, its anatomic and physiologic substrate and its mechanism are not clear.

Inflammation is proposed as a potential mechanism for fatigue in MS but has the lack of sufficient evidence. ${ }^{3}$ Abnormalities in functional connectivity of the resting default mode network have been linked with fatigue in MS. ${ }^{9}$ However, the biological processes underlying these abnormalities are not known.

Microglial activation may play a role in the pathogenesis of MS, ${ }^{10,11}$ but it has not been systematically studied in relation to MS-associated fatigue (MSAF). [F-18]PBR06 is a secondgeneration, longer half-life PET radioligand, targeting the $18-\mathrm{kDa}$ translocator protein for noninvasive assessment of cerebral microglial activation that we have recently reported to be increased in subcortical gray matter and normal-appearing white matter in MS. ${ }^{12-17}$ Our aim is to assess the role of microglial activation in MSAF using [F-18]PBR06 PET.

\section{Methods}

\section{Participants}

Participants were recruited from the Partners Multiple Sclerosis Center at the Brigham and Women's Hospital and through an online recruitment portal for healthy control participants (HCs). Initially, 18 participants with MS and 12 HC participants were consecutively enrolled. Two participants with MS and $2 \mathrm{HC}$ participants were low-affinity binders and were excluded from the study (see the Genotyping section below). Four additional patients with MS subsequently changed their minds about participating in the study or were lost to follow-up following consent. Twelve patients with MS (5 SP and 7 RR; 8 women and 4 men) and $10 \mathrm{HC}$ participants (4 women and 6 men) completed the study. Table 1 contains a summary of characteristics for all study participants, and table 2 contains detailed individualized participant characteristics. Our findings regarding the relationship of the [F-18]PBR06 PET scans from these patients with MS with disability and brain atrophy were previously reported. ${ }^{16}$

In terms of the inclusion criteria, we included patients with SPMS if they experienced a worsening of their EDSS score by at least 0.5 (if their baseline EDSS score was $\geq 5.5$ ) or at least 1.0 (if their baseline EDSS score was $<5$ ) over a period of 1 year before PET scanning. In addition, we included patients with RRMS who had a relapse or if there was evidence of a new or enlarging T2 bright lesion on MRI or a gadoliniumenhancing lesion on T1-weighted MRI in the last year. Patients who were treated with corticosteroids during a period of 1 month before the PET scan were excluded. PET scanning was performed within a median time interval of 5.1 (range 1.1-25.6) weeks in relation to the subjects' clinical assessment. Patients did not experience a relapse between the clinical and PET imaging visits.

\section{Standard protocol approvals, registrations, and patient consents}

The clinicaltrials.gov ID for our study is NCT02649985. The study was approved and overseen by the Institutional Review Board, Radiation Safety Committee, and Radioactive Drug Research Committee at our hospital. Written informed consent was obtained from all study participants before participation.

\section{Genotyping}

Blood samples were collected during the initial visits, and genotyping was performed for screening purposes. Genotyping used a TaqMan assay to identify the DNA polymorphism of the translocator protein (TSPO) gene on chromosome 22q13.2. Study participants with high-affinity $(\mathrm{HAB})$ and medium-affinity binding $(\mathrm{MAB})$ were included in the study, whereas ones with low-affinity binding were excluded. Among the 12 patients with MS who completed the study, 7 were HABs and 5 were MABs. Among the HC participants, 6 were $\mathrm{HABs}$ and 4 were MABs (table 1). The 
Table 1 Summary of participant characteristics

\begin{tabular}{llll}
\hline & MS $(\mathbf{N}=\mathbf{1 2})$ & HC (N = 10) & $p$ Value \\
\hline Age (y) & $42 \pm 11.7$ & $46 \pm 15.5$ & 0.54 \\
\hline Sex distribution & $7 \mathrm{~F}, 5 \mathrm{M}$ & $4 \mathrm{~F}, 6 \mathrm{M}$ & 0.39 \\
\hline TSPO binding affinity & 7 high, 5 medium & 6 high, 4 medium \\
\hline Median EDSS score & 3.5 & \\
\hline MFIS score & $36 \pm 21$ & \\
\hline MFIS physical score & $17 \pm 10$ & \\
\hline MFIS cognitive score & $17 \pm 10$ & \\
\hline MFIS psychosocial score & $3 \pm 2$ & \\
\hline HDRS score & $5 \pm 6.5$ & \\
\hline
\end{tabular}

Abbreviations: EDSS = Expanded Disability Status Scale; HC = healthy control; HDRS = Hamilton Depression Rating Scale; MFIS = Modified Fatigue Impact Scale; TSPO $=$ translocator protein.

Data are mean $\pm S D$, unless otherwise indicated.

proportion of HABs and MABs in the MS and $\mathrm{HC}$ groups was not significantly different (table 1 ).

\section{Radiopharmaceutical production}

We have previously described the radiopharmaceutical production methodology at our center. ${ }^{16}$

\section{MRI acquisition and corresponding analysis}

Each study participant completed an MRI scan on the same scanner (Siemens 3T Skyra, Erlangen, Germany) according to a previously described acquisition protocol. ${ }^{18-20}$ The protocol included a 2D T1-weighted spin-echo axial series (repetition time $=611-943 \mathrm{~ms}$, echo time $=7.9 \mathrm{~ms}$, and voxel size $=0.43 \times$ $0.43 \times 3 \mathrm{~mm}^{3}$ ) and a 3D fluid-attenuated inversion recovery and magnetization-prepared rapid gradient-echo series (voxel sizes for both $1 \times 1 \times 1 \mathrm{~mm}^{3}$ ). Using a previously reported technique, normalized whole-brain parenchymal volume (BPV) was derived by applying the latter images to a fully automated algorithm (SIENAX, v. 5.0; Analysis Group, fsl.fmrib.ox.ac.uk.) $)^{21}$

Hyperintense lesions on 3D T2 FLAIR and hypointense lesions on T1-weighted spin-echo images were marked by a trained observer (K.C.) and verified by a senior observer (S.T. or T.S.). We determined that to qualify as a T1 hypointense lesion, the lesion had to be both hypointense on T1-weighted images and hyperintense on Fluid Attenuation Inversion Recovery (FLAIR) images. ${ }^{22,23}$ A semiautomated edge-finding tool was then used for volumetric lesion contouring using Jim (version 7; Xinapse Systems, West Bergholt, United Kingdom; xinapse.com). Our previous work has shown high reliability for this semiautomated method of measuring MS cerebral lesion burden. ${ }^{22,23}$

\section{PET acquisition and corresponding analysis}

[F-18]PBR06 was injected as a bolus injection for PET scanning using an IV catheter into an arm or hand vein; images were acquired in a list mode acquisition mode using a highresolution PET/CT scanner (GE Discovery ECAT, Waukesha, WI). Statistical Parametric Mapping (SPM) was used as the primary analysis technique for this study. SPM12 software (the Wellcome Institute of Cognitive Neurology, London, United Kingdom; fil.ion.ucl.ac.uk/spm/software/) was used to process the [F-18]PBR06 PET SUV images. ${ }^{24}$ PET images were stereotactically normalized to the Montreal Neurologic Institute version of Talairach space. Whole-brain multiple linear regression modeling of the within-group effects of SUV images was used on a voxel-by-voxel basis to examine their association with Modified Fatigue Impact Scale (MFIS) as the main regressor, and age, sex, and global SUV as covariates of no interest, in an analysis of covariance (ANCOVA) setting. These group-level correlation effect estimates generated statistical parametric maps of the $t$-statistic that demonstrated the ageadjusted and sex-adjusted correlations of MFIS total and subscale scores with PET uptake in the MS group.

Furthermore, we coregistered the summed [F-18]PBR06PET images acquired 60-90 minutes following tracer injection to the individual MRIs and segmented the images into gray and white matter regions of interest, and subregions as defined by the automated anatomical labeling (AAL) atlas template, ${ }^{25}$ using PNEURO 3.8 software (PMOD Technologies, Zurich, Switzerland; pmod.com/web/). This is an automated pipeline and reduces risk of operator-dependent bias in region-of-interest delineation. To account for interparticipant differences, partial volume-corrected SUV ratios (SUVRs) were calculated for participants based on normalization of the individual region's $S V_{60-90}$ to the global brain SUV $_{60-90}$, similar to our previous reports. ${ }^{16,26-28}$ SUVRs for individual supratentorial AAL template regions of interest (ROIs) were also obtained and assessed for correlations with fatigue scores. Because the substantia nigra (SN) showed the strongest significant correlations with fatigue scores on SPM 
Table 2 Detailed participant characteristics

\begin{tabular}{|c|c|c|c|c|c|c|c|c|c|c|c|c|}
\hline $\begin{array}{l}\text { Participant } \\
\text { number }\end{array}$ & Sex & $\begin{array}{l}\text { Age } \\
\text { (y) }\end{array}$ & $\begin{array}{l}\text { TSPO } \\
\text { binding } \\
\text { affinity }\end{array}$ & Group & $\begin{array}{l}\text { Disease } \\
\text { duration } \\
\text { (y) }\end{array}$ & $\begin{array}{l}\text { Current } \\
\text { DMT }\end{array}$ & $\begin{array}{l}\text { EDSS } \\
\text { score }\end{array}$ & MFIS & $\begin{array}{l}\text { MFIS } \\
\text { Physical }\end{array}$ & $\begin{array}{l}\text { MFIS } \\
\text { Cognitive }\end{array}$ & $\begin{array}{l}\text { MFIS } \\
\text { Psychosocial }\end{array}$ & HDRS \\
\hline 1 & $\mathrm{~F}$ & 37 & $\mathrm{HAB}$ & RRMS & 5.2 & Fingolimod & 4 & 64 & 25 & 35 & 4 & 13 \\
\hline 2 & M & 37 & $\mathrm{HAB}$ & RRMS & 19.6 & Rituximab & 3 & 33 & 12 & 19 & 2 & 1 \\
\hline 3 & $\mathrm{~F}$ & 34 & MAB & RRMS & 4.8 & Fingolimod & 1 & 16 & 7 & 9 & 0 & 0 \\
\hline 4 & M & 32 & MAB & RRMS & 11.9 & Fingolimod & 1 & 15 & 13 & 2 & 0 & 1 \\
\hline 5 & $\mathrm{~F}$ & 23 & $\mathrm{HAB}$ & RRMS & 8.2 & Natalizumab & 1.5 & 6 & 2 & 3 & 1 & 0 \\
\hline 6 & $\mathrm{~F}$ & 41 & $\mathrm{HAB}$ & RRMS & 9.6 & Fingolimod & 1.5 & 21 & 9 & 9 & 3 & 17 \\
\hline 7 & $\mathrm{~F}$ & 27 & MAB & RRMS & 3.5 & Fingolimod & 2 & 37 & 15 & 20 & 2 & 0 \\
\hline 8 & M & 52 & MAB & SPMS & 14.9 & Rituximab & 6.5 & 15 & 8 & 6 & 1 & 0 \\
\hline 9 & M & 53 & $\mathrm{HAB}$ & SPMS & 19 & Rituximab & 6 & 37 & 21 & 15 & 1 & 2 \\
\hline 10 & $\mathrm{~F}$ & 59 & MAB & SPMS & 19 & $\begin{array}{l}\text { Glatiramer } \\
\text { acetate }\end{array}$ & 6 & 54 & 23 & 25 & 6 & 7 \\
\hline 11 & $\mathrm{~F}$ & 59 & $\mathrm{HAB}$ & SPMS & 19 & None & 6.5 & 71 & 34 & 29 & 8 & 17 \\
\hline 12 & $\mathrm{~F}$ & 50 & $\mathrm{HAB}$ & SPMS & 17 & Rituximab & 4.5 & 62 & 31 & 26 & 5 & 2 \\
\hline 13 & M & 25 & MAB & $\mathrm{HC}$ & & & & & & & & \\
\hline 14 & $\mathrm{~F}$ & 45 & $\mathrm{HAB}$ & $\mathrm{HC}$ & & & & & & & & \\
\hline 15 & M & 60 & MAB & $\mathrm{HC}$ & & & & & & & & \\
\hline 16 & $\mathrm{~F}$ & 25 & $\mathrm{HAB}$ & $\mathrm{HC}$ & & & & & & & & \\
\hline 17 & $\mathrm{~F}$ & 34 & MAB & $\mathrm{HC}$ & & & & & & & & \\
\hline 18 & M & 33 & $\mathrm{HAB}$ & $\mathrm{HC}$ & & & & & & & & \\
\hline 19 & M & 70 & MAB & $\mathrm{HC}$ & & & & & & & & \\
\hline 20 & M & 65 & $\mathrm{HAB}$ & $\mathrm{HC}$ & & & & & & & & \\
\hline 21 & M & 48 & $\mathrm{HAB}$ & $\mathrm{HC}$ & & & & & & & & \\
\hline 22 & $\mathrm{~F}$ & 54 & $\mathrm{HAB}$ & $\mathrm{HC}$ & & & & & & & & \\
\hline
\end{tabular}

Abbreviations: DMT = disease-modifying treatment; EDSS = Expanded Disability Status Scale; HAB = high-affinity binding; HDRS = Hamilton Depression Rating Scale; MAB = medium-affinity binding; MFIS = Modified Fatigue Impact Scale, HC = healthy control; RRMS = relapsing-remitting MS; SP = secondary progressive MS; TSPO = translocator protein.

Disease duration refers to time from first MS symptom onset.

analysis, the SN region was specifically segmented using the Hammers atlas applied to PET images in the standard space using PVIEW tool of PMOD 3.8 platform. SN SUVRs were calculated based on Hammers atlas brain parenchymal ROIs delineated in PVIEW without partial volume correction owing to the small size of the SN ROI. PET uptake in right, left and average of right and left SN ROIs were further investigated for group differences between participants with MS with fatigue and participants with MS without fatigue (defined as MFIS >37 and MFIS $\leq 37$, respectively) and HCs and for correlations with MFIS and its subscales in participants with MS. In addition, for illustration purposes, individualized maps of increased substantia nigra PET uptake in a patient with MS with fatigue and a patient with MS without fatigue, represented as voxel-based z-score values $>2$ compared with a healthy data set of 9 healthy volunteers were generated, using the PNEURO platform.

\section{Patient-reported outcome measures}

Participants with MS completed the following patient-reported outcome measures: MFIS ${ }^{29}$ and Hamilton Depression Rating Scale (HDRS). ${ }^{30}$ The MFIS is a 21 -item fatigue scale with 5 scaled responses ranging from "never" to "almost always". Total fatigue scores as well as physical, cognitive, and psychosocial subscale scores are derived. The HDRS is a 17 -item rating scale that evaluates the severity of depression symptoms using a semistructured interview.

\section{Statistical analysis}

The exact Wilcoxon-Mann-Whitney test with accompanying exact Hodges-Lehmann 95\% CIs was used to evaluate group differences in SUVRs. Associations were evaluated using Pearson correlations and partial correlations, with 95\% CIs calculated using the Fisher transformation. The study's nature 
was exploratory as a relatively large number of regions were evaluated; therefore, results should be considered hypothesis generating.

\section{Data availability}

After due anonymization, we will make any unpublished study data available for sharing with other qualified investigators, if requested.

\section{Results}

\section{Relationship of MFIS with MRI and clinical parameters}

BPV was lower in patients with MS $(\mathrm{n}=12)$ compared with HCs $(\mathrm{n}=9)(1,402.8 \pm 57.1 \mathrm{~mL}$ vs $1,475.1 \pm 66.9 \mathrm{~mL})$, but there was no correlation between BPV and total MFIS or its physical, cognitive, or psychosocial subscale scores $(\mathrm{r}=-0.05$, $-0.09,-0.02$, and $0.004, \mathrm{n}=12$ ). There was no correlation between MFIS and T1 lesion volume $(r=0.002, n=12)$ or T2 lesion volume $(\mathrm{r}=-0.11, \mathrm{n}=12)$. In terms of clinical correlations, MFIS increased with increasing age and EDSS (both $\mathrm{r}=0.58)$ and a positive correlation with increasing HDRS $(\mathrm{r}=0.52)$.

\section{SPM analysis}

\section{Voxel-level correlations of PET uptake with MFIS}

Strongest voxel-wise peaks for age- and sex-adjusted correlation with MFIS (figure 1A) were seen in the right SN (T-score 4.67), left SN (T-score 4.25), cerebellar vermis, right inferior cerebellar cortex ( $\mathrm{T}$-scores 4.23 and 4.15, respectively), bilateral angular gyri (T-scores 4.22 and
4.18 for the right and left side, respectively), right precuneus ( $\mathrm{T}$-score 4.21), left premotor and supplemental motor area (BA6) (T-score 4.08), and juxtacortical white matter ( $\mathrm{T}$-score 4.06, figure $1 \mathrm{~B}$ ). A complete list of regions with voxels demonstrating peak positive correlations between PET uptake and MFIS with $p<0.01$ is provided in table 3 .

Strongest voxel-wise peaks for negative correlations with MFIS were seen in the right orbital inferior frontal gyrus (BA 47) (T-score 4.03) and the right temporal pole (BA 38) (T-score 3.14).

\section{Regional analysis}

\section{Relationship of substantia nigra PET uptake with MFIS in MS}

The finding of strongest correlation between fatigue scores and PET in the $\mathrm{SN}$ was endorsed by a regional analysis as well. On regional analysis, there was a significant correlation between the SUVR in the SN and total MFIS score $(r=0.76$, $95 \%$ CI 0.33 to 0.93 , figure $2 \mathrm{~A}$ ). The correlation coefficients of right and left SN SUVRs with total MFIS (figure 2B) were 0.795 (95\% CI 0.41 to 0.94 ) and 0.427 (95\% CI -0.20 to $0.80)$, respectively.

An overall model consisting of right SN SUVR, age, EDSS, and HDRS explained the majority of variability of MFIS in participants with MS $\left(\mathrm{r}^{2}=0.7751\right.$, adjusted $\mathrm{r}^{2}=0.6466, \mathrm{n}=$ 12) with right SN SUVR remaining an independent predictor of MFIS ( $r=0.73$, 95\% CI 0.14 to $0.94, p=0.02$ ) after adjustment for the other covariates.

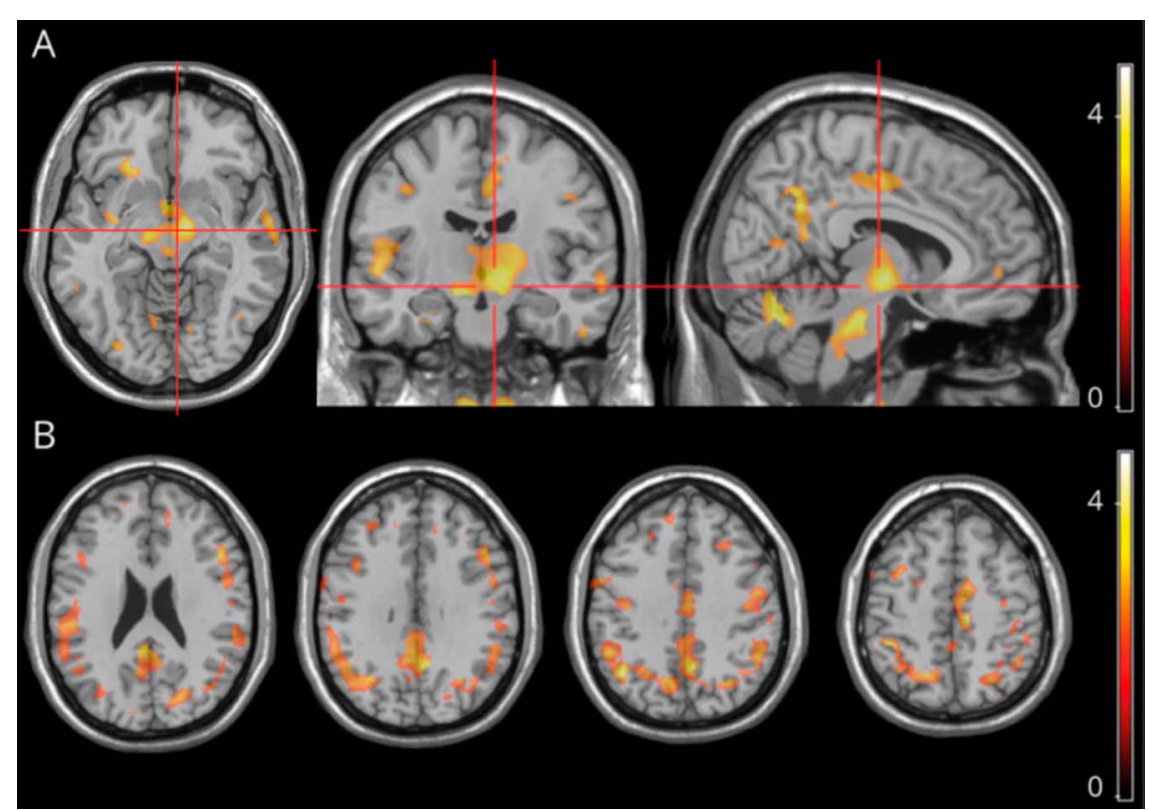

(A) Statistical Parametric Mapping (SPM)-based, voxel-by-voxel maps of correlation between Modified Fatigue Impact Scale (MFIS) and PET uptake. The strongest positive correlation was seen in the right substantia nigra (cross-bars). Additional regions of significant correlations were seen in the left substantia nigra, periaqueductal gray, pons, medulla, precuneus, midcingulate, cerebellar vermis, and insular cortex regions. (B) SPM-based, voxel-by-voxel maps demonstrate widespread positive correlation in juxtacortical white matter between MFIS scores and PET uptake. 
Table 3 SPM voxel level correlations with MFIS scores

\begin{tabular}{|c|c|c|c|}
\hline Brodmann area description & $\begin{array}{l}\text { MNI coordinates } \\
(x, y, \text { and } z)\end{array}$ & Peak-level $t$ value & Peak-level $z$ value \\
\hline \multicolumn{4}{|l|}{ Positive correlations } \\
\hline \multicolumn{4}{|l|}{ Brainstem } \\
\hline Right substantia nigra & $10,-16,-14$ & 4.67 & 3.05 \\
\hline Left substantia nigra & $-10,-10,-10$ & 4.25 & 2.89 \\
\hline Pons & $-8,-24,-28$ & 3.98 & 2.79 \\
\hline Medulla & $-2,-34,-48$ & 3.90 & 2.75 \\
\hline Midbrain: periaqueductal gray (PAG) & $4,-30,-18$ & 3.44 & 2.55 \\
\hline \multicolumn{4}{|l|}{ Frontal lobe } \\
\hline Left premotor cortex and supplementary motor area (BA6) & $-12,-24,48$ & 4.08 & 2.83 \\
\hline Left pars opercularis of the inferior frontal gyrus, Broca area (BA44) & $-50,20,26$ & 3.84 & 2.73 \\
\hline Right Broca area (BA45) & $40,30,2$ & 3.13 & 2.40 \\
\hline Right insula (BA13) & $32,28,0$ & 3.20 & 2.43 \\
\hline Right dorsolateral and medial prefrontal cortex (BA9) & $8,46,36$ & 3.04 & 2.35 \\
\hline \multicolumn{4}{|l|}{ Parietal lobe } \\
\hline Right parietal lobe including the angular gyrus near the TPO junction (BA39) & $40,-62,40$ & 4.22 & 2.88 \\
\hline Right precuneus (BA7) & $42,-42,50$ & 4.21 & 2.88 \\
\hline Left parietal lobe including the angular gyrus near the TPO junction (BA39) & $-50,-54,42$ & 4.18 & 2.87 \\
\hline Left dorsal posterior cingulate area (BA31) & $-6,-56,34$ & 3.93 & 2.77 \\
\hline Left precuneus (BA7) & $-20,-68,38$ & 3.23 & 2.45 \\
\hline Right inferior parietal lobe/supramarginal gyrus, parietal operculum (BA40) & $58,-32,26$ & 3.03 & 2.35 \\
\hline \multicolumn{4}{|l|}{ Temporal lobe } \\
\hline Right fusiform (BA37) & $46,-54,-2$ & 3.63 & 2.64 \\
\hline Right PrimAuditory (BA41) & $54,-12,0$ & 3.41 & 2.54 \\
\hline Left superior temporal gyrus, included in the Wernicke area (BA22) & $-60,-6,-10$ & 3.21 & 2.44 \\
\hline Right parahip (BA36) & $28,-16,-26$ & 3.18 & 2.42 \\
\hline Left middle temporal gyrus/auditory cortex (BA21) & $-64,-18,-12$ & 3.12 & 2.39 \\
\hline \multicolumn{4}{|l|}{ Occipital lobe } \\
\hline Right PrimVisual (BA17) & $12,-66,10$ & 3.42 & 2.54 \\
\hline Right extra striate cortex; receives input from pulvinar (BA19) & $30,-82,-14$ & 3.38 & 2.52 \\
\hline Right VisualAssoc (BA18) & $16,-92,10$ & 3.17 & 2.41 \\
\hline \multicolumn{4}{|l|}{ Cerebellum } \\
\hline Cerebellar vermis & $-2,-70,-20$ & 4.23 & 2.89 \\
\hline Right inferior cerebellar cortex & $14,-74,-46$ & 4.15 & 2.85 \\
\hline Left superior cerebellar cortex & $-38,-52,-24$ & 3.86 & 2.74 \\
\hline Right superior cerebellar cortex & $18,-62,-18$ & 3.25 & 2.46 \\
\hline Left cerebellar cortex & $-46,-60,-32$ & 3.18 & 2.42 \\
\hline Left inferior cerebellar cortex & $-24,-42,-54$ & 3.09 & 2.38 \\
\hline
\end{tabular}


Table 3 SPM voxel level correlations with MFIS scores (continued)

\begin{tabular}{llll}
\hline Brodmann area description & $\begin{array}{c}\text { MNI coordinates } \\
(\mathbf{x}, \mathbf{y}, \text { and } \mathbf{z})\end{array}$ & Peak-level $\boldsymbol{t}$ value & Peak-level z value \\
\hline White matter & & & \\
\hline Subcortical/juxtacortical WM & $26,-62,34$ & 4.06 & 2.82 \\
\hline Juxtacortical/deep WM in the left occipital lobe & $-20,-76,16$ & 3.44 & 2.55 \\
\hline JWM: right frontal (inferior occipitofrontal fascicle) & $24,24,-10$ & 3.39 & 2.52 \\
\hline Right inferior occipitofrontal fasciculus & $32,-6,-10$ & 3.27 & 2.47 \\
\hline Right frontal JWM & $32,-20,42$ & 3.22 & 2.44 \\
\hline Negative correlations & & \\
\hline Orbital part of the right inferior frontal gyrus (BA47) & $30,22,-26$ & 4.03 \\
\hline Right temporal pole (BA38) & $20,6,-46$ & 3.14 \\
\hline
\end{tabular}

Abbreviations: JWM = juxtacortical white matter; MFIS = Modified Fatigue Impact Scale; SPM = Statistical Parametric Mapping; TPO = temporoparietooccipital. $p<0.01$.

There was no significant correlation between MFIS and global brain microglial activation $(\mathrm{r}=-0.01,95 \% \mathrm{CI}-0.58$ to 0.57$)$ or between MFIS and total brainstem microglial activation ( $\mathrm{r}$ $=0.24,95 \% \mathrm{CI}-0.39$ to 0.71 ). When analyzed separately, both patients with RRMS and SPMS showed at least a trend for an increase in the MFIS increasing right SN SUVR ( $\mathrm{r}=$ $0.70,95 \% \mathrm{CI}-0.11$ to 0.95 for RRMS [ $=7$ ], and $\mathrm{r}=0.94$, $95 \%$ CI 0.33 to 0.99 for SPMS [ $=5]$, respectively).

\section{Additional regional correlations of PET with total MFIS}

In addition, on segmentation of the brain using the AAL template, significant increases in MFIS were seen with increasing SUVRs in the right parahippocampus $(\mathrm{r}=0.75,95 \% \mathrm{CI} 0.31$ to 0.93 ), right precuneus ( $\mathrm{r}=0.65,95 \% \mathrm{CI} 0.13$ to 0.89 ), and left putamen ( $\mathrm{r}=0.62,95 \%$ CI 0.07 to 0.88$)$ in patients with MS. Among these regions, after adjustment for age and EDSS, right precuneus remained significantly correlated with MFIS $(\mathrm{r}=$ $0.65,95 \%$ CI 0.03 to 0.91 ) in patients with MS.

\section{Correlations between MFIS subscales and PET in MS on regional analysis}

\section{Cognitive subscale of the MFIS}

The SN SUVR correlated significantly with the cognitive subscale of the MFIS ( $r=0.71,95 \%$ CI 0.23 to 0.91 , figure 2C) that remained significant after adjustment for age and EDSS ( $\mathrm{r}$ $=0.65,95 \%$ CI 0.04 to 0.91 ). Again, the right SN SUVR showed a significant correlation with the cognitive subscale $(0.84,95 \%$ CI 0.51 to 0.95$)$ that also remained significant after adjustment for age and EDSS ( $\mathrm{r}=0.84,95 \%$ CI 0.45 to 0.96$)$. The left SN SUVR did not show a significant correlation with cognitive MFIS ( $r=0.30,95 \%$ CI -0.33 to 0.75 ).

On segmentation of the brain using the AAL template, significant increases were seen in PET uptake increases in the cognitive subscale of the MFIS in the right precuneus $(r=0.71$, $95 \%$ CI 0.22 to 0.91$)$ and the right parahippocampus ( $r=0.67$, $95 \%$ CI 0.16 to 0.90 ). Among these regions, after adjustment for age and EDSS, the right precuneus remained significantly correlated with cognitive MFIS ( $r=0.78,95 \%$ CI 0.29 to 0.95 ) in patients with MS.

\section{Physical subscale of the MFIS}

The SN SUVR also correlated significantly with the physical subscale of the MFIS ( $r=0.774,95 \%$ CI 0.36 to 0.93 , figure 2D) that remained significant after adjustment for age and EDSS ( $r=$ $0.64,95 \%$ CI 0.03 to 0.91 ). There was a significant correlation between the right SN SUVR and the physical subscale of the MFIS (0.68, 95\% CI 0.17 to 0.90$)$ that also remained significant after adjustment for age ( $r=0.68,95 \%$ CI 0.36 to 0.93$)$ but not after adjustment for both age and EDSS $(r=0.59,95 \% \mathrm{CI}-0.06$ to 0.89 ). The correlation between the left SN SUVR and the MFIS physical subscale showed a trend but did not attain statistical significance ( $r=0.56,95 \% \mathrm{CI}-0.02$ to 0.86 ).

On segmentation of the brain, using the AAL template, significant increases were seen in PET uptake with increasing values of the physical subscale of MFIS in the left calcarine gyrus ( $r=0.59,95 \% \mathrm{CI} 0.02$ to 0.87$)$, right parahippocampus ( $r=0.77,95 \%$ CI 0.34 to 0.93$)$, left putamen $(r=0.66,95 \% \mathrm{CI}$ 0.13 to 0.89$)$, right thalamus $(\mathrm{r}=0.64,95 \% \mathrm{CI} 0.10$ to 0.89$)$, and vermis $10(\mathrm{r}=0.66,95 \% \mathrm{CI} 0.14$ to 0.90$)$. A decrease in PET uptake with increasing values of the physical subscale of MFIS was seen in the left superomedial frontal gyrus $(\mathrm{r}=$ $-0.62,95 \%$ CI -0.88 to -0.07 ).

\section{Psychosocial subscale of the MFIS}

The correlation between the average SN SUVR and the psychosocial MFIS subscale did not attain statistical significance $(r=0.556,95 \% \mathrm{CI}-0.03$ to 0.86$)$, but the right $\mathrm{SN}$ 

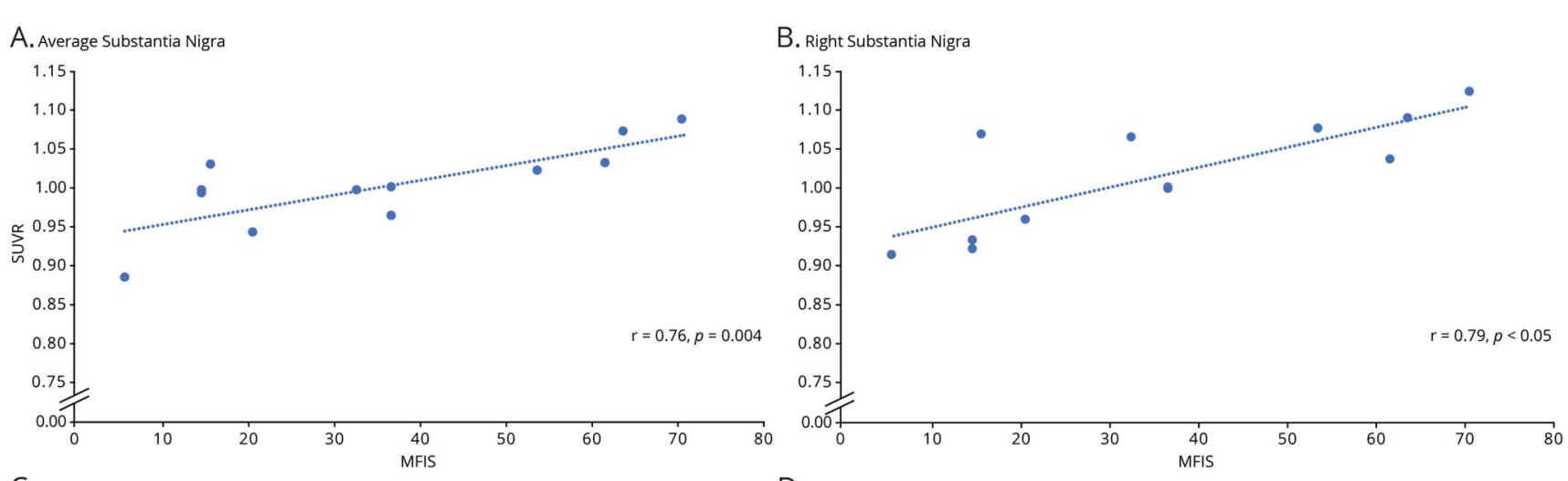

C. Average Substantia Nigra

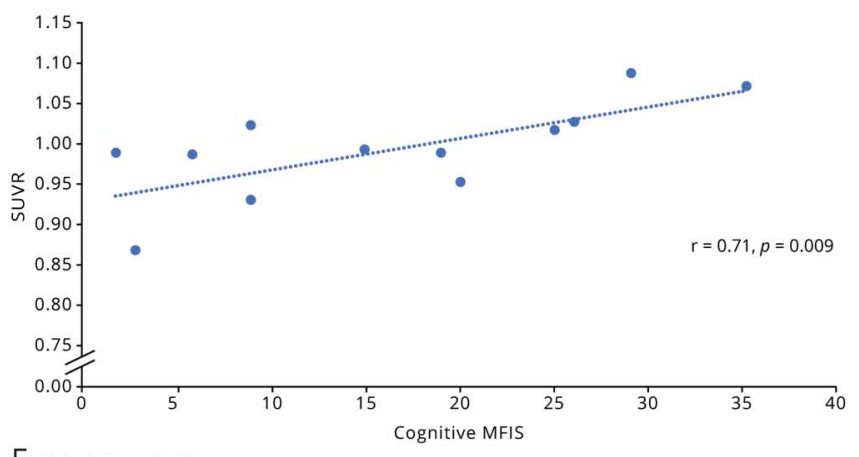

D. Average Substantia Nigra
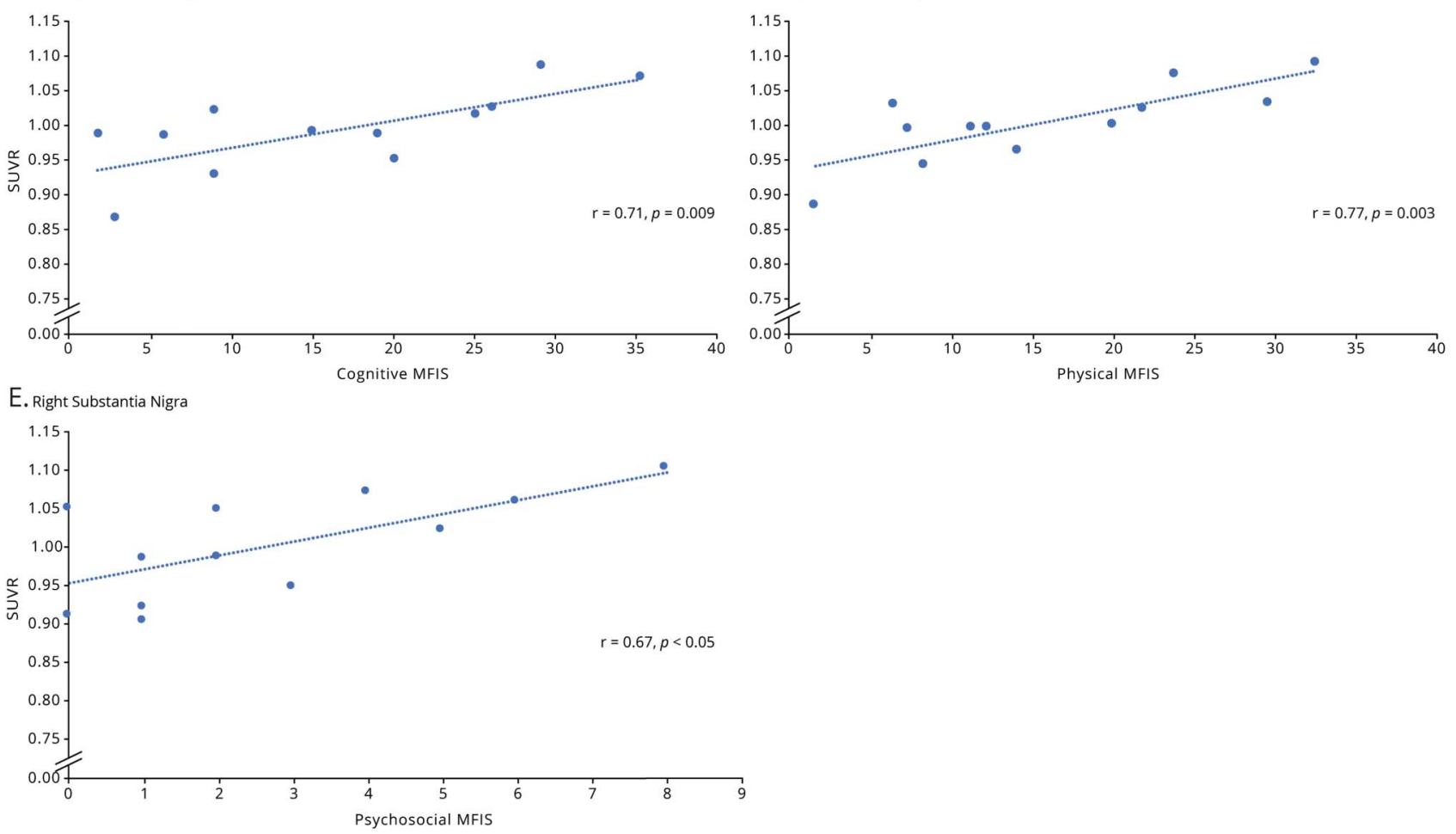

Correlations between (A) average substantia nigra (SN) SUVR and total MFIS, (B) right SN SUVR and total MFIS, (C) average SN SUVR and cognitive MFIS, (D) average SN SUVR and physical MFIS, and (E) right SN SUVR and psychosocial MFIS. MFIS = Modified Fatigue Impact Scale.

SUVR showed a significant correlation with the psychosocial subscale of the MFIS ( $r=0.67,95 \%$ CI 0.16 to 0.90 , figure 2E). The left SN SUVR did not show a significant correlation with the psychosocial subscale of the MFIS $(r=0.22,95 \% \mathrm{CI}$ -0.40 to 0.71 ).

On segmentation of the brain using the AAL template, significant increases were seen in PET uptake with increasing values of the psychosocial subscale of MFIS in the left cuneus ( $\mathrm{r}=0.58,95 \% \mathrm{CI} 0.01$ to 0.87 ), right parahippocampus ( $\mathrm{r}=0.66,95 \% \mathrm{CI} 0.14$ to 0.90$)$, and vermis $10(\mathrm{r}=0.58,95 \% \mathrm{CI} 0.02$ to 0.87$)$. A decrease in PET uptake with increasing values of the psychosocial subscale of MFIS was seen in vermis $12(\mathrm{r}=-0.59,95 \% \mathrm{CI}-0.87$ to -0.04$)$.

\section{Group comparisons of SN PET uptake between patients with MS with fatigue and patients with MS without fatigue and HCs}

MFIS scores were 6-37 in patients with MS without fatigue and 54 to 71 in patients with MS with fatigue. The SN SUVR was higher in participants with MS with fatigue compared with participants with MS without fatigue and $\mathrm{HC}$ participants $(1.053 \pm 0.031$ vs $0.976 \pm 0.045$ vs $0.932 \pm 0.069$; $95 \%$ CI for effect size [ES] 0.03 to 0.14 and 0.03 to 0.21 , respectively, figures 3, A and B). Similarly, the right SN SUVR was also higher in participants with MS with fatigue compared with participants with MS without fatigue and HC participants $(1.066 \pm 0.034$ vs $0.971 \pm 0.059$ vs $0.933 \pm 0.102$; $95 \%$ CI for ES 0.02 to 0.16 and 0.03 to 0.26 , respectively, figure 3C). The left SN SUVR was higher in participants with MS 
Figure 3 Comparison of substantia nigra PET uptake between subjects with MS with fatigue and subjects with MS without fatigue and healthy participants

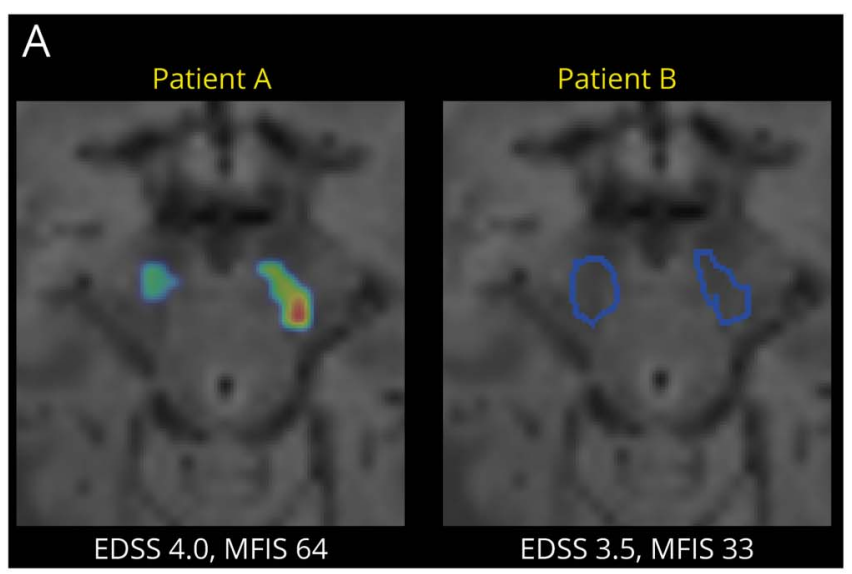

C. Right Substantia Nigra

MS with fatigue vs MS without fatigue, $p<0.05$ MS with fatigue vs HC $p<0.05$

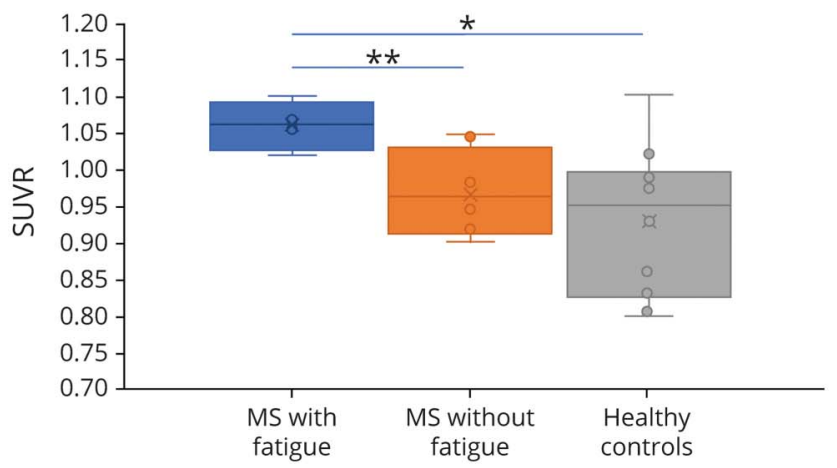

\section{B. Average Substantia Nigra}

MS with fatigue vs MS without fatigue, $p<0.05$ MS with fatigue vs HC $p<0.05$

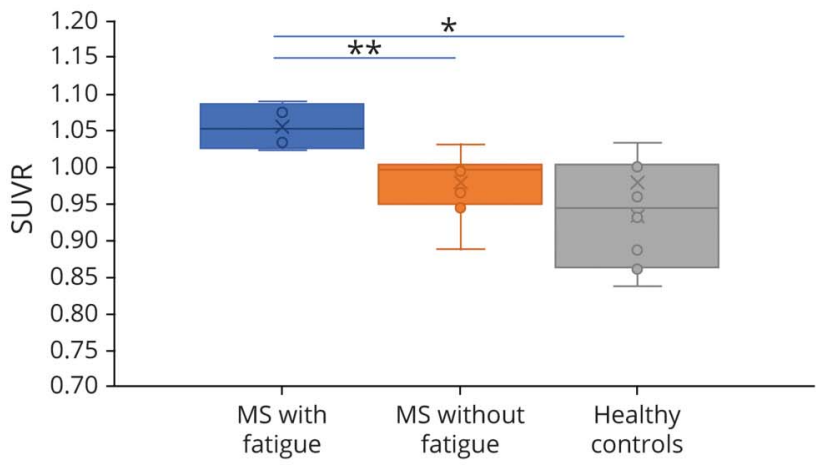

D. Left Substantia Nigra

MS with fatigue vs $\mathrm{HC} p<0.05$

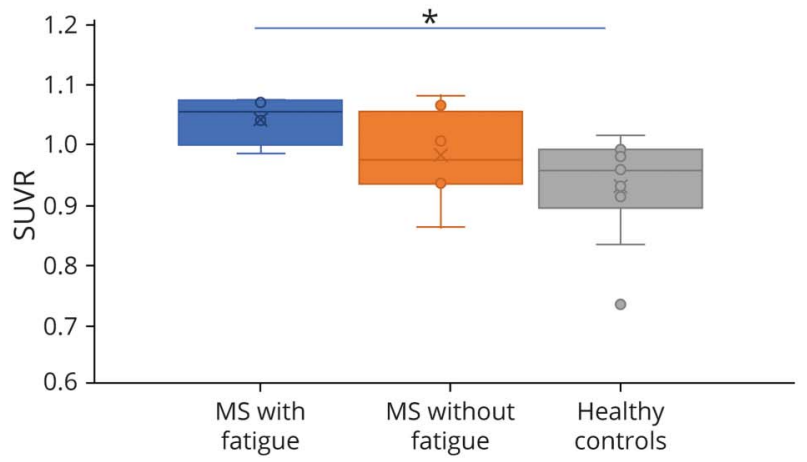

(A) Individualized z-score maps showing increased [F-18]PBR06 PET uptake in the bilateral substantia nigra in a patient with MS with fatigue with a high total MFIS score (total MFIS score $=64$ ) compared with a patient with MS without fatigue with a comparable EDSS score (3.5 vs 4) and a low total MFIS score (MFIS score $=33$ ). For the latter patient, the ROIs for the substantia nigra are delineated but do not demonstrate an increased $z$-score of $>2$ compared with a healthy control group. (B) Increased average substantia nigra SUVR in patients with MS with fatigue compared with patients with MS without fatigue and healthy participants. (C) Increased right substantia nigra SUVR in patients with MS with fatigue compared with patients with MS without fatigue and healthy participants. (D) Increased left substantia nigra SUVR in patients with MS with fatigue compared with healthy controls. MFIS = Modified Fatigue Impact Scale. ${ }^{\star} p<0.05 ;{ }^{* \star} p<0.01$.

with fatigue compared with HC participants $(1.041 \pm 0.041$ vs $0.930 \pm 0.085,95 \%$ CI for ES 0.03 to 0.24$)$ but not as compared to participants with MS without fatigue (1.041 \pm 0.041 vs $0.980 \pm 0.073,95 \%$ CI for ES -0.03 to 0.13$)$ (figure 3D).

\section{Group comparisons of PET uptake in AAL template regions between patients with MS with fatigue and patients with MS without fatigue and HCs}

Among the AAL template regions that showed correlations with MFIS or its subscales in patients with MS, only the right parahippocampus and right thalamus showed increased SUVRs in patients with MS with fatigue compared with HCs $(1.0 \pm 0.056$ vs $0.92 \pm 0.13$ and $1.24 \pm 0.08$ vs $1.12 \pm 0.11$, respectively), but they were not statistically significant $(95 \%$ CI for ES -0.04 to 0.21 and -0.05 to 0.27 ).

\section{Discussion}

The major findings of our study are that substantia nigra microglial activation is linked to fatigue scores in patients with MS and that patients with MS with fatigue have a higher substantia nigra microglial activation than HCs. Specifically, right substantia nigra microglial activation correlated with fatigue scores in patients with MS, independent of age, disability, and depression severity, highlighting the potential specificity of this observation. On subsequent exploratory analysis, we found correlation of fatigue scores with microglial activation in widespread cortical and subcortical gray matter regions, including the right precuneus, parahippocampal gyrus, putamen, thalamus, and juxtacortical white matter.

It has been previously proposed that fatigue in MS is linked to regional changes rather than global brain damage. ${ }^{31}$ Rocca 
et al. ${ }^{31}$ found that total lesional load measured on T2- and T1weighted MRIs and global brain atrophy did not distinguish patients with MS with fatigue from patients with MS without fatigue. Instead, injury to strategic gray and white matter regions manifesting as atrophy and microstructural changes measured on diffusion tensor imaging significantly contributed to fatigue in MS. The lack of correlations between BPV and total T2- and T1 lesional load with fatigue scores in our study is consistent with these observations. Other studies have found, in terms of anatomic substrates, abnormalities in corticocortical connections, corticostriatal networks, deep gray matter structures, and a cortico-striato-thalamo-cortical loop in relation to fatigue in $\mathrm{MS}^{32}$ In terms of functional and molecular changes, abnormalities in the dopaminergic system (dopamine hypothesis), ${ }^{33}$ the neuroendocrine system involving the hypothalamo-pituitary axis (neuroendocrine hypothesis), ${ }^{34}$ and altered functional connectivity of the resting default mode network (functional disconnection hypothesis) 35,36 have been linked to fatigue in MS in various studies, but the underlying biological bases of these abnormalities are not known. $^{32,37}$ Microglial activation may represent a unifying mechanism underlying these myriad abnormalities detected in patients with MS with fatigue. It is also possible, however, that some of these changes are linked to fatigue in general rather than being specific for MS-related fatigue. Notably, inflammation in widespread cortical areas has been associated with severity of symptoms in patients with chronic fatigue syndrome (CFS)/myalgic encephalomyelitis. ${ }^{38}$

Abnormal functional activation of the $\mathrm{SN}$ in association with fatigue $^{39}$ has been previously reported in patients with MS. This is consistent with our results, and the microglial activation in the SN may underly the reported abnormal functional activation in this population. The $\mathrm{SN}$ is a major seat of dopaminergic neurons in the brain, and microglial activation in the SN may be linked to dopaminergic imbalance, which has also been proposed as a potential mechanism for MS-related fatigue. ${ }^{33}$ Increased iron accumulation in the $\mathrm{SN}^{40}$ has previously been reported in MS, but its association with fatigue in MS has not been studied.

Moreover, a brainstem fatigue generator model has been proposed in postviral fatigue syndromes and fatigue that follows poliomyelitis ${ }^{41}$ that may be relevant for understanding fatigue in MS. In this model, a central role of substantia nigra lesions in inhibiting the functional activity of thalamus, cerebral cortex, and reticular formation via decreased dopaminergic stimulation of the putamen and resultant excitation of the globus pallidus externa and inhibition of the globus pallidus interna has been proposed. $^{41,42}$ Recently, a fatigue nucleus that is triggered by cytokines produced by neuroinflammation has been postulated to be responsible for the behavioral changes seen in CFS. $^{43}$ Further studies are albeit needed to directly assess the associations of substantia nigra microglial activation with regional and widespread metabolic, electrophysiologic, and neurochemical alterations and to assess whether the SN could be the fatigue nucleus in MS.
The association of [F-18]PBR06 PET uptake in the parahippocampal gyrus, posterior cingulate, and precuneus cerebral cortical areas, with fatigue scores, supports the role of microglial activation in these regions in the manifestation of fatigue in MS. Precuneus is a hub of the default mode network (DMN). ${ }^{44}$ Microglial activation may play a role in the reported abnormalities in functional connectivity of the DMN, which has been linked with fatigue in MS. ${ }^{9}$ Parahippocampal gyrus has been reported to connect the default mode network with the memory system in the medial temporal lobe. ${ }^{45}$ Inflammation of the parahippocampus, precuneus, and posterior cingulate may interfere with physiologic activation and deactivation of the DMN and retrieval of memory, contributing to fatigue in patients with MS. ${ }^{45}$ The association of right parahippocampal microglial activity with psychosocial fatigue is consistent with its role in affective and cognitive empathy ${ }^{46}$ and detecting sarcasm in interpersonal interactions. ${ }^{47}$ More studies are needed to assess the relationship between gray matter inflammation and fatigue in MS and their modification by various treatment approaches.

Our study has several limitations. The sample size is small, and our results need to be confirmed in larger studies. The crosssectional and observational design of our study allows us to explore an association between microglial activation and $\mathrm{fa}$ tigue, but does not allow us to establish causality. We did not formally assess cognition and sleep disturbances, although none of our participants with MS were diagnosed with a sleep disorder. Our conclusions rest on the validity of the MFIS, which is a subjective scale but has been otherwise validated in the assessment of fatigue in MS. Other brainstem nuclei such as locus coeruleus may be involved in fatigue pathogenesis in MS, but our approach may lack the resolution and statistical power to detect changes in this small-sized structure. ${ }^{48}$ TSPO is not completely specific for micrgolia, and approximately $20 \%$ of the PET signal may originate from astrocytes expressing glial fibrillary acid protein. ${ }^{49}$

Future research studies are needed to compare the fatiguerelated microglial changes in MS with other diseases such as CFS and Parkinson disease and identify common and diseasespecific mechanisms of fatigue in neurologic disorders. Studies with a longitudinal design can help evaluate a causal relationship between microglial activation and fatigue in MS. Link of microglial activation with neurochemical and regional neurodegenerative changes in the context of MS-related fatigue also needs to be further investigated. Furthermore, the prognostic value of fatigue and related microglial activation in the context of progressive MS is also a potentially exciting area for further research.

Widespread microglial activation, particularly in the $\mathrm{SN}$, is linked to fatigue in MS. Such findings, if replicated and expanded, could provide a foundation for novel therapeutic strategies and targets for fatigue in MS. Further evaluation of neuroimmunologic basis of fatigue in MS is warranted. 


\section{Acknowledgment}

The authors gratefully acknowledge the participation of our patients and contributions of the staff of Biomedical Imaging Research Core and PET technologists in the Division of Nuclear Medicine and Molecular Imaging, Department of Radiology at Brigham and Women's Hospital.

\section{Study funding}

The authors gratefully acknowledge research grants from Nancy Davis Foundation's "Race to Erase MS" program, Ann Romney Center for Neurologic Diseases, Harvard Neuro-Discovery Center, and Water Cove Charitable Foundation for their support of this work. Funding agencies did not have any role in the performance of the research or preparation of the manuscript.

\section{Disclosure}

T. Singhal, S. Cicero, H. Pan, K. Carter, S. Dubey, R. Chu, B. Glanz, S. Hurwitz, S. Tauhid, M. Park, M. Kijewski, and E. Stern report no disclosures relevant to the manuscript. Dr. Bakshi has received consulting fees from Bayer, Biogen, Celgene, EMD Serono, Genentech, Guerbet, SanofiGenzyme, and Shire and research support from EMD Serono and Sanofi-Genzyme. D. Silbersweig reports no disclosures relevant to the manuscript. H.L. Weiner has received consulting fees from Biogen, Tiziana, Novartis, Merck Serono, and Teva Neurosciences and has received grant support from Merck Serono and Sanofi-Genzyme and Verily Life Sciences. Go to Neurology.org/NN for full disclosures.

\section{Publication history}

Received by Neurology: Neuroimmunology \& Neuroinflammation March 24, 2020. Accepted in final form June 18, 2020.

Appendix Authors

\begin{tabular}{|c|c|c|}
\hline Name & Location & Contribution \\
\hline $\begin{array}{l}\text { Tarun } \\
\text { Singhal, MD }\end{array}$ & $\begin{array}{l}\text { Brigham and Women's } \\
\text { Hospital, Harvard Medical } \\
\text { School, Boston, MA }\end{array}$ & $\begin{array}{l}\text { Designed and } \\
\text { conceptualized the study; } \\
\text { major role in the acquisition } \\
\text { of data; analyzed and } \\
\text { interpreted the data; } \\
\text { drafted and revised the } \\
\text { manuscript for intellectual } \\
\text { content; and provided } \\
\text { funding }\end{array}$ \\
\hline
\end{tabular}

\begin{tabular}{lll}
\hline $\begin{array}{l}\text { Steven } \\
\text { Cicero, BS }\end{array}$ & $\begin{array}{l}\text { Brigham and Women's } \\
\text { Hospital, Harvard Medical } \\
\text { School, Boston, MA }\end{array}$ & $\begin{array}{l}\text { Major role in the acquisition } \\
\text { of data and analyzed and } \\
\text { interpreted the data }\end{array}$ \\
\hline $\begin{array}{l}\text { Hong Pan, } \\
\text { PhD }\end{array}$ & $\begin{array}{l}\text { Brigham and Women's } \\
\text { Hospital, Harvard Medical } \\
\text { School, Boston, MA }\end{array}$ & $\begin{array}{l}\text { Analyzed and interpreted } \\
\text { the data and revised the } \\
\text { manuscript for intellectual } \\
\text { content }\end{array}$ \\
\hline $\begin{array}{l}\text { Kelsey } \\
\text { Carter, BS }\end{array}$ & $\begin{array}{l}\text { Brigham and Women's } \\
\text { Hospital, Harvard Medical }\end{array}$ & $\begin{array}{l}\text { Major role in the acquisition } \\
\text { of data and analyzed and } \\
\text { interpreted the data }\end{array}$ \\
\hline $\begin{array}{l}\text { Shipra } \\
\text { Dubey, PhD }\end{array}$ & $\begin{array}{l}\text { Brigham and Women's } \\
\text { Hospital, Harvard Medical } \\
\text { School, Boston, MA }\end{array}$ & $\begin{array}{l}\text { Designed and } \\
\text { conceptualized the study } \\
\text { and major role in the } \\
\text { acquisition of data }\end{array}$ \\
& &
\end{tabular}

Appendix (continued)

\begin{tabular}{|c|c|c|}
\hline Name & Location & Contribution \\
\hline $\begin{array}{l}\text { Renxin Chu, } \\
\text { PhD }\end{array}$ & $\begin{array}{l}\text { Brigham and Women's } \\
\text { Hospital, Harvard Medical } \\
\text { School, Boston, MA }\end{array}$ & $\begin{array}{l}\text { Analyzed and interpreted } \\
\text { the data }\end{array}$ \\
\hline $\begin{array}{l}\text { Bonnie } \\
\text { Glanz, PhD }\end{array}$ & $\begin{array}{l}\text { Brigham and Women's } \\
\text { Hospital, Harvard Medical } \\
\text { School, Boston, MA }\end{array}$ & $\begin{array}{l}\text { Analyzed and interpreted } \\
\text { the data and revised the } \\
\text { manuscript for intellectual } \\
\text { content }\end{array}$ \\
\hline $\begin{array}{l}\text { Shelley } \\
\text { Hurwitz, } \\
\text { PhD }\end{array}$ & $\begin{array}{l}\text { Brigham and Women's } \\
\text { Hospital, Harvard Medical } \\
\text { School, Boston, MA }\end{array}$ & $\begin{array}{l}\text { Analyzed and interpreted } \\
\text { the data and revised the } \\
\text { manuscript for intellectual } \\
\text { content }\end{array}$ \\
\hline $\begin{array}{l}\text { Shahamat } \\
\text { Tauhid, MD }\end{array}$ & $\begin{array}{l}\text { Brigham and Women's } \\
\text { Hospital, Harvard Medical } \\
\text { School, Boston, MA }\end{array}$ & $\begin{array}{l}\text { Analyzed and interpreted } \\
\text { the data }\end{array}$ \\
\hline $\begin{array}{l}\text { Mi-Ae Park, } \\
\text { PhD }\end{array}$ & $\begin{array}{l}\text { Brigham and Women's } \\
\text { Hospital, Harvard Medical } \\
\text { School, Boston, MA }\end{array}$ & $\begin{array}{l}\text { Analyzed and interpreted } \\
\text { the data and revised the } \\
\text { manuscript for intellectual } \\
\text { content }\end{array}$ \\
\hline
\end{tabular}

\begin{tabular}{|c|c|c|}
\hline $\begin{array}{l}\text { Marie } \\
\text { Kijewski, } \\
\text { DSc }\end{array}$ & $\begin{array}{l}\text { Brigham and Women's } \\
\text { Hospital, Harvard Medical } \\
\text { School, Boston, MA }\end{array}$ & $\begin{array}{l}\text { Designed and } \\
\text { conceptualized the study; } \\
\text { analyzed and interpreted } \\
\text { the data; and revised the } \\
\text { manuscript for intellectual } \\
\text { content }\end{array}$ \\
\hline
\end{tabular}

\begin{tabular}{ll}
\hline Emily Stern, & Brigham and Women's \\
MD & Hospital, Harvard Medical \\
& School, Boston, MA
\end{tabular}

Designed and

conceptualized the study; analyzed and interpreted the data; and revised the manuscript for intellectual content

\begin{tabular}{ll}
\hline Rohit & Brigham and Women's \\
Bakshi, MD, & Hospital, Harvard Medical \\
MA & School, Boston, MA
\end{tabular}

Designed and conceptualized the study; revised the manuscript for intellectual content; and provided funding

\begin{tabular}{lll}
\hline $\begin{array}{l}\text { David } \\
\text { Silbersweig, } \\
\text { MD }\end{array}$ & $\begin{array}{l}\text { Brigham and Women's } \\
\text { Hospital, Harvard Medical } \\
\text { School, Boston, MA }\end{array}$ & $\begin{array}{l}\text { Analyzed and interpreted } \\
\text { the data and revised the } \\
\text { manuscript for intellectual } \\
\text { content }\end{array}$ \\
\hline $\begin{array}{l}\text { Howard L. } \\
\text { Weiner, MD }\end{array}$ & $\begin{array}{l}\text { Brigham and Women's } \\
\text { Hospital, Harvard Medical } \\
\text { School, Boston, MA }\end{array}$ & $\begin{array}{l}\text { Designed and } \\
\text { conceptualized the study; } \\
\text { revised the manuscript for } \\
\text { intellectual content; and } \\
\text { provided funding }\end{array}$ \\
& & \\
\hline
\end{tabular}

\section{References}

1. Calabrese M, Rinaldi F, Grossi P, et al. Basal ganglia and frontal/parietal cortical atrophy is associated with fatigue in relapsing-remitting multiple sclerosis. Mult Scler 2010;16:1220-1228.

2. Comi G, Leocani L, Rossi P, Colombo B. Physiopathology and treatment of fatigue in multiple sclerosis. J Neurol 2001;248:174-179.

3. Newland P, Starkweather A, Sorenson M. Central fatigue in multiple sclerosis: a review of the literature. J Spinal Cord Med 2016;39:386-399.

4. Krupp LB, Serafin DJ, Christodoulou C. Multiple sclerosis-associated fatigue. Expert Rev Neurother 2010;10:1437-1447.

5. Feinstein A, Freeman J, Lo AC. Treatment of progressive multiple sclerosis: what works, what does not, and what is needed. Lancet Neurol 2015;14:194-207.

6. Fischer A, Heesen C, Gold SM. Biological outcome measurements for behavioral interventions in multiple sclerosis. Ther Adv Neurol Disord 2011;4:217-229.

7. van der Vuurst de Vries RM, van den Dorpel JJ, Mescheriakova JY, et al. Fatigue after a first attack of suspected multiple sclerosis. Mult Scler 2018;24:974-981.

8. Cavallari M, Palotai M, Glanz BI, et al. Fatigue predicts disease worsening in relapsingremitting multiple sclerosis patients. Mult Scler 2016;22:1841-1849.

9. Bisecco A, Nardo FD, Docimo R, et al. Fatigue in multiple sclerosis: the contribution of resting-state functional connectivity reorganization. Mult Scler 2018;24: $1696-1705$. 
10. Gandhi R, Laroni A, Weiner HL. Role of the innate immune system in the pathogenesis of multiple sclerosis. J Neuroimmunol 2010;221:7-14.

11. Weiner HL. The challenge of multiple sclerosis: how do we cure a chronic heterogeneous disease? Ann Neurol 2009;65:239-248.

12. Fujimura Y, Kimura Y, Simeon FG, et al. Biodistribution and radiation dosimetry in humans of a new PET ligand, (18)F-PBR06, to image translocator protein (18 kDa). J Nucl Med 2010;51:145-149.

13. Fujimura Y, Zoghbi SS, Simeon FG, et al. Quantification of translocator protein (18 $\mathrm{kDa}$ ) in the human brain with PET and a novel radioligand, (18)F-PBR06. J Nucl Med 2009;50:1047-1053.

14. James ML, Belichenko NP, Nguyen TV, et al. PET imaging of translocator protein (18 $\mathrm{kDa}$ ) in a mouse model of Alzheimer's disease using N-(2,5-dimethoxybenzyl)-2-18Ffluoro-N-(2-phenoxyphenyl)acetamide. J Nucl Med 2015;56:311-316.

15. Lartey FM, Ahn GO, Shen B, et al. PET imaging of stroke-induced neuroinflammation in mice using [18F]PBR06. Molecular imaging and biology. Mol Imaging Biol 2014; 16:109-117.

16. Singhal T, O'Connor K, Dubey S, et al. Gray matter microglial activation in relapsing vs progressive MS: a [F-18]PBR06-PET study. Neurol Neuroimmunol Neuroinflamm 2019;6:e587. doi:10.1212/NXI.0000000000000587.

17. Singhal T, O'Connor K, Dubey S, et al. 18F-PBR06 versus 11C-PBR28 PET for assessing white matter translocator protein binding in multiple sclerosis. Clin Nucl Med 2018;43:e289-e295.

18. Dupuy SL, Tauhid S, Hurwitz S, Chu R, Yousuf F, Bakshi R. The effect of dimethyl fumarate on cerebral gray matter atrophy in multiple sclerosis. Neurol Ther 2016;5:215-229.

19. Kim G, Chu R, Yousuf F, et al. Sample size requirements for one-year treatment effects using deep gray matter volume from $3 \mathrm{~T} \mathrm{MRI} \mathrm{in} \mathrm{progressive} \mathrm{forms} \mathrm{of} \mathrm{multiple} \mathrm{scle-}$ rosis. Int J Neurosci 2017;127:971-980.

20. Meier DS, Guttmann CRG, Tummala S, et al. Dual-sensitivity multiple sclerosis lesion and CSF segmentation for multichannel 3T brain MRI. J Neuroimaging 2018;28:36-47.

21. Chu R, Tauhid S, Glanz BI, et al. Whole brain volume measured from 1.5T versus 3T MRI in healthy subjects and patients with multiple sclerosis. J Neuroimaging 2016;26: 62-67.

22. Bermel RA, Sharma J, Tjoa CW, Puli SR, Bakshi R. A semiautomated measure of whole-brain atrophy in multiple sclerosis. J Neurol Sci 2003;208:57-65.

23. Ceccarelli A, Jackson JS, Tauhid S, et al. The impact of lesion in-painting and registration methods on voxel-based morphometry in detecting regional cerebral gray matter atrophy in multiple sclerosis. AJNR Am J Neuroradiol 2012;33:1579-1585.

24. Friston KJ, Penny WD, Nichols TE, Kiebel SJ, Ashburner JT. Statistical Parametric Mapping. The Analysis of Functional Brain Images. London, UK: Elsevier Ltd.; 2007.

25. Tzourio-Mazoyer N, Landeau B, Papathanassiou D, et al. Automated anatomical labeling of activations in SPM using a macroscopic anatomical parcellation of the MNI MRI single-subject brain. NeuroImage 2002;15:273-289.

26. Singhal T, O'Connor K, Pan H, Dubey S, et al. The relationship of microglial activation and multiple sclerosis-associated fatigue: a [F-18]PBR06 PET study. Berlin, Germany: ECTRIMS; 2018.

27. Singhal T, O'Connor K, Chu R, Tauhid S, et al. [F-18]PBR06 vs. [C-11]PBR28 PET for Assessing White Matter TSPO Binding in Multiple Sclerosis. Paris, France: ECTRIMS/ACTRIMS; 2017.

28. Singhal T, O'Connor K, Chu R, Tauhid S, et al. [F-18]PBR06 PET to Assess TSPO Binding and its Association with Brain Atrophy and Disability in Multiple Sclerosis. Paris, France: ECTRIMS/ACTRIMS; 2017.
29. Kos D, Kerckhofs E, Carrea I, Verza R, Ramos M, Jansa J. Evaluation of the modified fatigue impact scale in four different European countries. Mult Scler 2005;11:76-80. 30. Williams JB. A structured interview guide for the Hamilton Depression Rating Scale Arch Gen Psychiatry 1988;45:742-747.

31. Rocca MA, Parisi L, Pagani E, et al. Regional but not global brain damage contributes to fatigue in multiple sclerosis. Radiology 2014;273:511-520.

32. Chalah MA, Riachi N, Ahdab R, Creange A, Lefaucheur JP, Ayache SS. Fatigue in multiple sclerosis: neural correlates and the role of non-invasive brain stimulation. Front Cell Neurosci 2015;9:460.

33. Dobryakova E, Genova HM, DeLuca J, Wylie GR. The dopamine imbalance hypothesis of fatigue in multiple sclerosis and other neurological disorders. Front Neurol 2015;6:52.

34. Burfeind KG, Yadav V, Marks DL. Hypothalamic dysfunction and multiple sclerosis: implications for fatigue and weight dysregulation. Curr Neurol Neurosci Rep 2016;16: 98.

35. Finke C, Schlichting J, Papazoglou S, et al. Altered basal ganglia functional connectivity in multiple sclerosis patients with fatigue. Mult Scler 2015;21:925-934.

36. Hidalgo de la Cruz M, d'Ambrosio A, Valsasina P, et al. Abnormal functional connectivity of thalamic sub-regions contributes to fatigue in multiple sclerosis. Mult Scler 2018;24:1183-1195.

37. Chalah MA, Ayache SS. Is there a link between inflammation and fatigue in multiple sclerosis? J Inflamm Res 2018;11:253-264.

38. Nakatomi Y, Mizuno K, Ishii A, et al. Neuroinflammation in patients with chronic fatigue syndrome/myalgic encephalomyelitis: an (1)(1)C-(R)-PK11195 PET study. J Nucl Med 2014;55:945-950.

39. Engstrom M, Flensner G, Landtblom AM, Ek AC, Karlsson T. Thalamo-striatocortical determinants to fatigue in multiple sclerosis. Brain Behav 2013;3:715-728.

40. Blazejewska AI, Al-Radaideh AM, Wharton S, et al. Increase in the iron content of the substantia nigra and red nucleus in multiple sclerosis and clinically isolated syndrome: a 7 Tesla MRI study. J Magn Reson Imaging 2015;41:1065-1070.

41. Chaudhuri A, Behan PO. Fatigue in neurological disorders. Lancet 2004;363: 978-988.

42. Bruno RL, Creange SJ, Frick NM. Parallels between post-polio fatigue and chronic fatigue syndrome: a common pathophysiology? Am J Med 1998;105:66S-73S

43. Komaroff AL. Advances in understanding the pathophysiology of chronic fatigue syndrome. JAMA . Epub 2019 Jul 5.

44. Raichle ME. The brain's default mode network. Annu Rev Neurosci 2015;38: 433-447.

45. Ward AM, Schultz AP, Huijbers W, Van Dijk KR, Hedden T, Sperling RA. The parahippocampal gyrus links the default-mode cortical network with the medial temporal lobe memory system. Hum Brain Mapp 2014;35:1061-1073.

46. Toller G, Adhimoolam B, Rankin KP, Huppertz HJ, Kurthen M, Jokeit H. Right fronto-limbic atrophy is associated with reduced empathy in refractory unilateral mesial temporal lobe epilepsy. Neuropsychologia 2015;78:80-87.

47. Rankin KP, Salazar A, Gorno-Tempini ML, et al. Detecting sarcasm from paralinguistic cues: anatomic and cognitive correlates in neurodegenerative disease. NeuroImage 2009;47:2005-2015.

48. Niepel G, Bibani RH, Vilisaar J, et al. Association of a deficit of arousal with fatigue in multiple sclerosis: effect of modafinil. Neuropharmacology 2013;64:380-388.

49. Kaunzner UW, Kang Y, Zhang S, et al. Quantitative susceptibility mapping identifies inflammation in a subset of chronic multiple sclerosis lesions. Brain 2019;142:133-145. 


\section{Neurology \\ Neuroimmunology \& Neuroinflammation}

\section{Regional microglial activation in the substantia nigra is linked with fatigue in MS \\ Tarun Singhal, Steven Cicero, Hong Pan, et al. \\ Neurol Neuroimmunol Neuroinflamm 2020;7; \\ DOI 10.1212/NXI.0000000000000854}

This information is current as of August 7, 2020

\section{Updated Information \& \\ Services}

References

Subspecialty Collections

Permissions \& Licensing

\section{Reprints}

including high resolution figures, can be found at:

http://nn.neurology.org/content/7/5/e854.full.html

This article cites 44 articles, 6 of which you can access for free at: http://nn.neurology.org/content/7/5/e854.full.html\#\#ref-list-1

This article, along with others on similar topics, appears in the following collection(s):

Multiple sclerosis

http://nn.neurology.org//cgi/collection/multiple_sclerosis

PET

http://nn.neurology.org//cgi/collection/pet

Information about reproducing this article in parts (figures,tables) or in its entirety can be found online at:

http://nn.neurology.org/misc/about.xhtml\#permissions

Information about ordering reprints can be found online:

http://nn.neurology.org/misc/addir.xhtml\#reprintsus

Neurol Neuroimmunol Neuroinflamm is an official journal of the American Academy of Neurology.

Published since April 2014, it is an open-access, online-only, continuous publication journal. Copyright

Copyright $\odot 2020$ The Author(s). Published by Wolters Kluwer Health, Inc. on behalf of the American

Academy of Neurology.. All rights reserved. Online ISSN: 2332-7812.

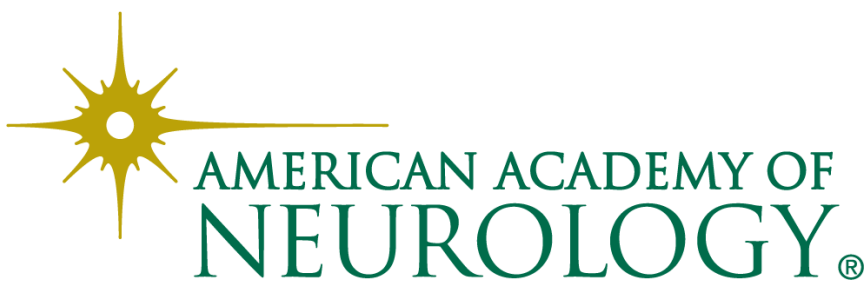

